make their work most valuable. They asked the further co-operation of Fellows of the Academy in this undertaking, and that of ophthalmologists outside of the Academy will be equally welcome. One or two well-studied cases are worth more in this connection than any number of cases in which the etiology has been guessed at.

The officers of the Academy for the coming year are: President, Emil Mayer of New York City; Vice Presidents, First, John R. Newcomb of Indianapolis; Second, R. F. Ridpath of Philadelphia; Third, William C. Finnoff of Denver; Secretary, Luther C. Peter of Philadelphia; Treasurer, Secord H. Large of Cleveland; Editor, Clarence Loeb of Chicago; Councillors, Horace Newhart of Minneapolis and E. C. Ellett of. Memphis. The committee in charge of the graduate teaching is Harry S. Gradle of Chicago, W. P. Wherry of Omaha, and Meyer Weiner of St. Louis. The next meeting is to be held in Philadelphia, the exact date to be fixed after consultation with the Fellows of that city.

E. J.

\section{THE JOURNAL YEAR}

We have no desire to dwell upon the difficulties this JourN AL has to meet and overcome in common with other journals, scientific and literary, in order to keep up its standards and continue publication. But an occasional frank statement regarding the situation seems due to our subscribers and contributors, who are seally partners in the enterprise.

During the past year we have had to meet two increases in cost of printing in all its departments, which amounted in the aggregate of 21 per cent.over the very high prices prevailing at the beginning of the year. The present contracts between the printing firms and the unions terminate in February, and if those who dominate the unions believe the state of the labor market makes it possible, there will doubtless be another increase at that time. It is impossible to get paper except by ordering months in advance, and then paying the price prevailing when it is delivered. Up to the present time this price has been moving upward.

Under these circumstances it has only been possible to continue the American JoUrnal of Ophithal mology and Ophthalmic Literature at their present level, by the cooperation of larger lists of subscribers than have ever before joined to sustain an ophthalmic journal. The continuance of this cooperation and support, in the prompt payment of their own subscriptions and in speaking of the publications to others (more than half the oculists of America still take no ophthalmic journal) will make it possible to continue our publication as we desire in spite of the adverse conditions.

During the past year, by publishing 12 numbers in 11 months, we have succeeded in bringing the date of publication to the first of each month, altho inadequate mail service has often delayed the delivery, and the mails seem particularly overburdened near the close of the political campaign.

Failure to pay promptly and keep the names on the regular subscription list is always a cause of increased expense and greatly increased labor for our office force. To all who will save us this expense we are glad to give something in return. We, therefore, will send to all subscribers, new or old, who pay before January 1, 1921, copies of one of the unlearnable test figures alluded to in our November issue, page 843. Additional time will be allowed for those who live outside of the United States. This is not a premium for subscribing; it is a premium for prompt payment..

The policy of the JourNaL will not be changed with reference to its associated publication, Ophthalmic Literature with its Yearbook Digest of the literature of ophthalmology, with- classified bibliographies. In this way our readers are given command of the literature of the world relating to ophthalmology, carefully classified, sifted and condensed. To meet the requirement of the post of fice department regarding such publications, a separate price has to be set upon 
each. But the price for the two will not be increased over that paid when they were issued together.

The Ophthalmic Publishing Co.

\section{BOOK NOTICES}

Ophthalmic Operations, edited by Harold Grimsdale, M. B., F. R. C. S., and Elmore Brewerton, F. R. C. S., 438 pages with index. London, Bailliere, Tindall \& Cox. Price, 18 shillings. 179 illustrations.

This is the second edition of this textbooks, the first having proved a reliable guide to the operator.

Not all operations, by any means have been considered by the authors and the choice will not appeal to every one; in fact, altho the book covers $43 \%$ pages, it is really a description of "some operations." These are succinctly described and are accompanied by diagramatic illustrations, which aid the understanding. For operations on the lids, the descriptions given are perhaps sufficient, but for intraocular operations, even those on cataract and glacoma, the descriptions are not quite those of the operations that may be commonly seen in America, i. e., the technic is somewhat different. Other operations, such as those on the cornea, muscles and foreign bodies in the eye, should have merited more exhaustive descriptions. The book is recommended as a reliable guide for the surgeon.

H. V.W.

Travaux Neurologiques de Guerre, Preface du Professeur Pierre Marie, by Georges Guillain and J. A. Barre. 463 pages with index and paper cover. Masson et Cie, Paris. Price, 18 francs.

This work on the Neurology of the Eye is an admirable exposè of work done during the war, being a collection of separate essays, part of which were published during that time in various French journals, describing injuries to the brain, spinal cord, their membranous and osseous covering and the peripheral nerves, organic lesions produced by action from a distance of explosions, commotions, etc.
The grouping of the work is original, especially that under Semiology of the Nerves, where the various reflexes are exhaustively studied, particularly the medio-plantar, tibio-femoral posterior and peroneo-femoral, which enrich the technic of examination and render clinicians a real service. In particular, the description of a large number of cases of complete section of the spinal cord is of interest. The first three chapters are taken up by semiology, particularly of the reflexes; the second part by injuries of the encephalon; the third with those of the spinal cord; the fourth with commotions of the brain and cord without external injury; the fifth with pathology of the cranial and spinal nerves, and the sixth with five separate essays.

It goes without saying that the structure of the eye and its nerves have been affected in a large proportion of the instances and cases cited in this book, and herein is the direct interest to the oculist, as these ocular conditions are cited in detail and accompanied by a number of illustrations. This is a work that marks an advance not only in the history of injuries, but as well in the technic of examination.

H. V. W.

Report of Transactions Heidelberg Ophthalmological Congress, Fortieth meeting, 1916. 536 pp. 110 illustrations. Compiled by A. Wagenmann, Secretary, Wiesbaden, J. F. Bergmann.

German publications are beginning to come to us thru regular trade channels. In this way we now have the above transactions, four years after the holding of the meeting therein reported. This fortieth meeting was held 53 years after the founding of the Society, more than three years having elapsed since the thirty-ninth meeting in May, 1913. The meeting was held in the midst of war which had been going on for two years, and was occupied chiefly by war ophthalmology.

There are papers and discussions on: The visual tracts and centers and their various injuries encountered from war wounds. The ophthalmoscopy of in- 